University of South Florida

DIGITAL COMMONS

Digital Commons @ University of

@ UNIVERSITY OF SOUTH FLORIDA

South Florida

\title{
Through the Eyes of Experts: a Socio-Cognitive Perspective on the Automation of Fingerprint Work
}

Christopher Davis

davisc@mail.usf.edu

Ellen M. Hufnagel

Follow this and additional works at: https://digitalcommons.usf.edu/fac_publications

Part of the Business Commons

\section{Recommended Citation}

MIS Quarterly 31(4): 681-703 (December 2007)

This Article is brought to you for free and open access by the USF Faculty Publications at Digital Commons @ University of South Florida. It has been accepted for inclusion in USF St. Petersburg campus Faculty Publications by an authorized administrator of Digital Commons @ University of South Florida. For more information, please contact digitalcommons@usf.edu. 


\section{Through the Eyes of Experts: a Socio-Cognitive Perspective on the Automation of Fingerprint Work}

Christopher J. Davis, PhD

University of South Florida, Saint Petersburg

College of Business

$1407^{\text {th }}$ Ave S COB 348

Saint Petersburg, FL

33701-5016

Telephone (727) 8734944

Fax (727) 8734192

davisc@stpt.usf.edu

Ellen M. Hufnagel, $\mathrm{PhD}$

University of South Florida, Saint Petersburg

College of Business

$1407^{\text {th }}$ Ave S COB 348

Saint Petersburg, FL

33701-5016

Telephone (727) 8734519

Fax (727) 8734192

hufnagel@stpt.usf.edu 


\section{Through the Eyes of Experts: a Socio-Cognitive Perspective on the Automation of Fingerprint Work}

\section{Acknowledgements}

The authors would like to thank Alison Watkins, $\mathrm{PhD}$ and Anol Bhattacherjee, PhD for their comments on earlier drafts of this paper. We would also like to thank the editors and reviewers for their insightful and constructive commentary. This research was supported in part by a grant from the Police Information Technology Organisation (CS420).

\section{Author Biographies}

Christopher J. Davis, PhD is an Assistant Professor of Information Systems at the University of South Florida St. Petersburg. His research explores the effects of information systems on the process and organization of work and has appeared in a range of journals, including Journal of Computer Information Systems, Communications of the ACM, International Journal of Technology and Human Interaction, Journal of Organizational Change Management and Systems Research and Behavioral Science

Ellen M. Hufnagel, PhD is Associate Professor of Information Systems at the University of South Florida St. Petersburg. Her research has appeared in a number of scholarly journals, including MIS Quarterly, Information Systems Research, Information \& Management, Software: Practice \& Experience, International Journal of Software Engineering and Knowledge Engineering, and Accounting, Management \& Information Technology. In addition, she has published articles on client/server computing in Network Computing and InformationWeek. 


\title{
Through the Eyes of Experts: a Socio-Cognitive Perspective on the Automation of Fingerprint Work
}

\begin{abstract}
Prior research on technological frames indicates that many of the difficulties associated with systems implementation stem from differences in the meanings users, managers, and system developers attribute to automation projects. Although the concept of technological frames has been used to explore the bases for intergroup conflict during implementation, it is also a useful device for probing more deeply into the effects complex systems have on users’ perceptions of their work and the role-altering effects of new technologies. Drawing upon Personal Construct Theory and Job Characteristics Theory, we adapted the Repertory Grid technique to explore the technology-in- use frames of a group of occupationally-certified fingerprint technicians (FPTs). Our investigation reveals the important role the FPTs' occupationally-defined values and norms played in structuring their existing work practices and the tensions produced by organizationallymandated efforts to restructure the logic of their expertise-based hierarchies. These insights illuminate the effects work redesign had on the FPTs' task environment, the process logic that guided specific work practices, and the roles defined by their expertise-based hierarchies, and provide a basis for understanding the FPTs' unanticipated reactions to it.
\end{abstract}

Keywords: Technological frames; Work re-design; Job Characteristics Theory; Personal Construct Theory; Repertory Grid; Technicians 
Davis, Christopher J. and Hufnagel, Ellen M.

MIS Quarterly 31 (2) June 2007, pp XX-XX

\section{INTRODUCTION}

New information systems (IS) can have many unintended organizational consequences due to their effects on the nature of work and the differing perceptions of those who use them (Gallivan 2001; Orlikowski 1993; Zuboff 1988). Because of their specialized interests, training, and experience, different organizational stakeholders may develop unique perspectives on the value of technology, ascribing meanings to systems that can be quite different from what developers and managers anticipated (Bechky 2003). Thus, understanding how the intended users perceive a system can be crucial to the success of an implementation project.

Today, many organizations employ a host of well-trained technicians whose specialized skills and knowledge sets them apart from more traditional organizational users (Barley 1996). In many cases, technical expertise is horizontally rather than vertically distributed (Zabusky 1997) and norms of practice are developed within the occupational community (Darr and Scarselletta 2002). Furthermore, some technical specialties evidence strong occupational control structures not unlike those of the formal professions (Abbott 1988). In these arrangements, an external occupational group controls entry to the technical community, specifying credentialing requirements, role expectations, and best practices. Occupational controls are important from an organizational perspective because they help to ensure that technicians are well qualified, having demonstrated an understanding of the underlying scientific principles and mastery of the tools and techniques associated with their craft. However, occupationally-defined norms of practice may at times conflict with organizationally-defined policies and procedures, creating dissonance for those whose work identities are closely tied to their professional affiliations (Wilensky 1964).

Information technologies (IT) can facilitate and enhance technical work, but they can also disrupt existing work processes and role relations within an occupational community if those charged with implementing a system fail to fully comprehend the values that guide the training 
Davis, Christopher J. and Hufnagel, Ellen M. MIS Quarterly 31 (2) June 2007, pp XX-XX

and certification of technical specialists. Lacking in-depth knowledge of the work itself, managers may learn too late that the policies and procedures they implement to control technical work "seriously impair the effective and efficient operation of the normative systems through which work is actually accomplished" (Nelson 1997: 157). Thus, it is especially important from a system design and implementation perspective to understand the criteria occupationally-organized technicians use to judge their own work and the issues they face when their values and expectations are at odds with those of the organizations in which they operate (Barley 1996; Bechky 2003; Whalley and Barley 1997).

This research explores the perceptions of a group of occupationally-certified technicians whose work processes were altered by the implementation of a new system. The data were gathered during the pilot testing of a large-scale forensic system designed to automate the work of fingerprint technicians ${ }^{1}$ (FPTs) at police agencies in the UK. Our goal was to understand how the FPTs' technology-in-use frames, i.e., their sense of how the new system would impact existing work practices (Davidson 2006), was influenced by their occupational norms and values.

The perspective we take draws upon socio-cognitive research in IS that explores the technological frames of meaning organization members use in evaluating new technology (Orlikowski and Gash 1994). Grounded in Personal Construct Theory, our work extends prior implementation research by using a combination of qualitative and quantitative techniques to enable the FPTs to identify and elaborate their own technology-in-use frames. Drawing upon Personal Construct Theory (Kelly 1955/1991), RepGrid analysis (Stewart 1997; Tan and Hunter 2002) and talkback interviews (Thomas and Harri-Augstein 1985), the cognitive frames of 24 fingerprint specialists were identified and compared, providing insights into their work processes

\footnotetext{
${ }^{1}$ The complexity of fingerprint work gives rise to a wide range of organizational roles, grades and titles. We use the generic term fingerprint technician to refer to all who engage in the practice of fingerprint identification, irrespective of their formal titles.
} 
Davis, Christopher J. and Hufnagel, Ellen M.

MIS Quarterly 31 (2) June 2007, pp XX-XX

and their concerns regarding the new system. Our findings reveal a complex web of connections between observable aspects of the task environment, their occupationally-defined control system, and the sense of occupational identity the FPTs derived from their work. Understanding these connections helped to explain why the FPTs failed to fully embrace a system that substantially improved their overall performance.

\section{STUDYING TECHNICIANS’ WORK: A SOCIO-COGNITIVE APPROACH}

Much of what we know about the work of technicians comes from a handful of ethnographic studies focusing on technicians who work in specialties such as computer support (Pentland 1992; Zabusky 1997), field service (Orr 1996), emergency medicine (Barley 1996; Nelson 1997), radiology (Barley 1986), and other science-related specialties (Barley and Bechky 1994). Reflecting on these studies, Barley and Orr (1997) noted that technicians' work differs from more traditional work in organizations, combining aspects of 'white-collar' and 'blue-collar' work and requiring a unique combination of theoretical and practical knowledge. Others argue that the collective effort required in the performance of technical work, the sharing of contextual knowledge within and among communities of practitioners, and the horizontal distribution of expertise increase the importance of understanding the settings in which technicians operate and their social identities relative to the organization as a whole (Pentland 1992; Van de Ven 2004). For example, Pentland's (1992) study of the technicians who staff software support lines highlights the conflicts that can develop when the organizational hierarchy with its vertical division of labor is at odds with the horizontal distribution of knowledge within a technical community. "Because vertical and horizontal models of social organization project different and somewhat contentious images of technical work, the technician's social identity represents an uneasy amalgam of conflicting roles, norms, and obligations” (Nelson 1997: 157-8). 
Davis, Christopher J. and Hufnagel, Ellen M. MIS Quarterly 31 (2) June 2007, pp XX-XX

The complexity of technical work and the organizational settings in which it occurs argue strongly for a socio-cognitive research approach. Socio-cognitive research is grounded in the belief that, as a result of past experience, people develop internal cognitive models that enable them to organize, make sense of, and integrate new information about the world around them (Berger and Luckmann 1967; Fiske and Taylor 1984). These mental frameworks provide a basis for individuals to theorize about cause and effect relationships, interpret the actions of others, and determine their own actions (Hufnagel and Conca 1994). Although initially posited to explain individual behavior, the concept of cognitive frames has been extended in recent years to facilitate our understanding of group and organizational level behavior (Porac et al. 1989). Groups have psychological significance for their members (Gibson 2001), uniting them via "unique social and cognitive repertoires that guide their interpretation of the world" (Sahay and Robey 1996: 259). Because knowledge evolves within a technical community via an ongoing process of posing and solving problems and revising routines and practices, members tend to develop shared perspectives and values that guide their day-to-day interactions. As a result, group members often respond in similar ways when confronted by changing circumstances.

Change is an integral part of all implementation projects. Thus, it is not surprising that some IS researchers have adopted a socio-cognitive approach in studying the implementation process. Orlikowski and Gash (1994) broke new ground in this area in studying the introduction of groupware in a professional services firm. They analyzed the shared perspectives of different organizational constituencies, arguing that the assumptions and expectations group members have regarding the application and consequences of IT form technological frames that influence their interaction with and assessment of IT artifacts. The frames they identified proved useful in understanding how various actors made sense of the new software, and incongruence between the 
Davis, Christopher J. and Hufnagel, Ellen M. MIS Quarterly 31 (2) June 2007, pp XX-XX

frames of the users and IS specialists helped to explain many of the difficulties encountered in this project.

Davidson (2002) adopted a similar approach in studying the requirements definition phase of a project at a large insurance company. After comparing the frames of system developers and users, she concluded that the salience of their cognitive frames changed over time in response to specific organizational events, triggering repeated reinterpretation of the project and its requirements.

Sahay and Robey (1996) studied the implementation of a geographical information system in two local government agencies, using a model that also linked social context with organizational processes. At one site, incongruence in the frames of users and developers had a negative effect on the implementation process; at the other, a high degree of congruence was found between the frames of technology-initiators and those responsible for training and system support. They concluded that understanding the meanings various groups assign to a technology and the complex interplay among them can help to explain why efforts to implement the same system in different settings may produce variable results.

Each of these studies identified a number of time- and context-dependent cognitive structures, reflecting the unique experiences of and interactions between organizational participants as they came to understand the technology and its effects on their work. The three sets of frames do, however, evidence some commonalities. Of particular interest here are the frames relating to the incorporation of IT into existing work practices - what Orlikowski and Gash referred to as the technology-in-use frame. This is an especially important frame from the perspective of work automation because it relates to "people's understanding of how technology will be used on a day-to-day basis and the likely or actual conditions and consequences associated with such use" (Orlikowski and Gash 1994: 183). Unfortunately, all of these studies were 
Davis, Christopher J. and Hufnagel, Ellen M.

MIS Quarterly 31 (2) June 2007, pp XX-XX

designed to identify the many different technological frames that guide organizational members’ sensemaking activities, rather than the framing process or the factors that help to shape specific frames. Thus, we know relatively little about the structural aspects of the technology-in-use frame or the intra- and extra-organizational influences that affect a group’s interpretive processes (Davidson 2006).

Our investigation takes a different approach to the study of technological frames by focusing specifically on the technology-in-use frame of a group of forensic technicians, in an effort to better understand its dimensionality, the historical influences that helped to shape it, and its effect on their perceptions of a system that substantially altered their work practices. Like the system studied by Sahay and Robey, this technology was designed to support technical work; however, the technicians we studied were members of an external occupational group that specified credentialing requirements and played a significant role in defining the conventions that guided day-to-day practice. Our goal was to make the FPTs' technology-in-use frame more tractable by identifying common themes as well as the influence their occupational control system had on their value perceptions and responses to the new system.

\section{RESEARCH CONTEXT}

Forensic information systems have evolved in recent years to exploit scientific breakthroughs in areas such as DNA profiling, fingerprint identification, and psychological profiling, adding to the array of technologies used in criminal investigations. Increasingly sophisticated fingerprint recognition systems have begun to transform fingerprint work with the goal of improving the efficiency and effectiveness of the underlying work processes. The system of interest in this research was the National Automated Fingerprint Identification System (NAFIS), which consists of a national database of criminal records and distributed processing modules designed to operate within the 43 police agencies in England and Wales. At the time of 
Davis, Christopher J. and Hufnagel, Ellen M. MIS Quarterly 31 (2) June 2007, pp XX-XX

this study, the NAFIS database was already one of the largest image storage systems in Europe, housing close to 90 million images that could be searched at a speed of one million fingerprint comparisons per second.

Investigating the impact of NAFIS on the technical work it was designed to support was challenging due to the scale of the system, the multi-site context in which it was implemented, and the fact that many FPTs had had little or no exposure to automated fingerprint identification systems while others had some familiarity with earlier automated systems. In addition, expertise levels varied considerably - many FPTs were fully-qualified experts, while others were serving in apprentice positions. To understand the changing context of their work, our methods had to provide a perspective that was both broad and deep to capture the essence of their work processes and the different perspectives of the technicians themselves.

\section{PERSONAL CONSTRUCT THEORY AND THE REPERTORY GRID}

Over the years, researchers who study work design have converged on a relatively short list of job characteristics that are believed to influence people's perceptions of their work. For example, Hackman and Oldham’s (1980) Job Characteristics Theory (JCT) differentiates the work people do in organizations based on five variables - skill variety, task identity, task significance, autonomy, and feedback - arguing that jobs rated highly along each of these dimensions have high motivating potential and produce greater job satisfaction. Although JCT and related theories of work design have spawned hundreds of studies, providing valuable insights into the nature of work in organizational settings, these efforts are broadly focused, largely reductionist in nature, and ignore both the social context in which work is performed (Marchese 1998) and the subjective experience of those who engage in it (Ilgen and Hollenbeck 1991). Thus, this method of characterizing work along a limited number of fixed dimensions is unlikely to produce a real understanding of the context-specific perceptions and values of those who engage in technical 
work. Furthermore, prior research suggests that attempts to force fit technicians into established occupational categories may mask key differences in their occupational identities and the meaning they ascribe to their work (Darr and Scarselletta 2002). To get a fuller picture of the FPTs' work and their perceptions of NAFIS, we grounded our investigation in Personal Construct Theory (PCT) and adapted the Repertory Grid technique to elicit their views of work, the values they embrace, and their expectations of the system, contrasting our findings with those found in the literature on job characteristics and work redesign.

PCT was developed by psychologist George Kelly (1955/1991) as a framework for understanding how people make sense of the world around them. Kelly argued that people act as lay epistemologists in their attempts to order and interpret their experiences, categorizing and discriminating between their experiences based on perceived similarities and differences. In doing so, they develop unique systems of interrelated personal constructs or "networks of meaning” (Ryle 1975) that enable them to anticipate the consequences of their actions and interpret the actions of others. Unlike the nomothetic constructs that underpin much contemporary research, personal constructs are idiographic and relativistic, describing a set of relations derived from each individual's personal experiences that act as a guide in subsequent sensemaking. If PCT were solely about individual perceptions, its usefulness in organizational contexts would be limited; however, Kelly was especially interested in the roles people play in social processes. He argued that the personal constructs people use to order their views of the world act as guides to individual action and are shared by relevant others, providing the foundation for interpersonal relations. Thus, PCT posits that people who share common experiences may develop similar personal construct systems, enabling them to construe one another's construction processes.

Translating PCT into practice, Kelly also developed a cognitive mapping technique called the Repertory Grid to elicit people's perceptions of similarity and difference, tapping into their 
Davis, Christopher J. and Hufnagel, Ellen M. MIS Quarterly 31 (2) June 2007, pp XX-XX

theories of how the world operates. Over time, PCT and RepGrid have become disconnected as researchers have adapted grid techniques, using them to answer a multitude of research questions. For example, RepGrid has been used to study consumer brand preferences (Mardsen and Littler 2000), cognitive inertia (Hodgkinson 1997), professional appraisers’ views of their job functions (Armstrong and Eden 1979), business-IT alignment (Tan 1999) and users’ perceptions of effective systems analysts (Hunter and Beck 2000). While RepGrid has proven useful in hundreds of studies independent of PCT (Fransella et al. 2004), we retained the link between theory and technique, using RepGrid to tap into the FPTs' perceptions, and PCT as a basis for analyzing and interpreting our results. As Neimeyer and Neimeyer (1985) point out, this linkage is important because it recognizes "the complex interconnectedness of the self and its social surroundings” (p. 345), permitting the researcher to focus on "not only what an individual sees as the recurring themes in personal relationships, but how he or she sees these themes as interrelated” (p. 331).

\section{RESEARCH METHODS}

\section{Selection of Participants}

Data were gathered from FPTs at eight of the 43 police agencies in the UK. The participating agencies were selected by the Police Information Technology Organization, the government agency that commissioned NAFIS, as representative in terms of their size, demographics (rural vs. urban), crime incidence, and experience with prior automated fingerprint identification systems (AFIS). Prospective participants were identified in collaboration with local management based on their availability and willingness to participate. Actual participants were then selected by the researchers to reflect a range in terms of lengths of service, job grades, expertise, and gender.

Four sites were members of a consortium that had substantial experience with earlier automated fingerprint recognition systems. The other four were less mature in this respect, 
providing relatively unsophisticated, locally-developed software to support specific tasks in a somewhat piecemeal fashion. One site had almost no automation in place beyond the PCs FPTs used to enter demographic data into the national database. For convenience sake, we refer to FPTs who had worked with earlier, less sophisticated AFIS as experienced; we refer to those who had had little or no exposure to such systems as inexperienced.

Differentiating novices from experts within a profession can be challenging, given the myriad ways expertise has been defined in the literature (Büssing and Herbig 2003). However, within the fingerprint community, the term expert has a specific meaning - it refers to those who have attained a particular status within their occupational group via an apprenticeship (5 years at the time of this study) and qualifying examinations. Thus, Fingerprint Expert is a formal designation and those so designated are considered qualified to present fingerprint evidence in court. In the sections that follow, we refer to all participants who had completed the credentialing process as experts, regardless of their actual titles or length of service.

Over the course of the study, 24 of the 208 FPTs at the eight sites (11.5\%) participated in RepGrid interviews - 13 females, 11 males. Their lengths of service ranged from 6 months to 33 years with a mean of 11.3 years and spanned a range of job grades. Table 1 shows the distribution of study participants based on expertise and prior AFIS experience.

Table 1 about here

\section{Data Collection}

Two rounds of interviews were conducted during the staggered pilot testing activities at each location with the goal of capturing the FPTs' technology-in-use frames while they were still actively engaged in making sense of the system. The time between interview rounds was approximately two to three months. The first round took place shortly after NAFIS was 
Davis, Christopher J. and Hufnagel, Ellen M.

MIS Quarterly 31 (2) June 2007, pp XX-XX

demonstrated and explained, providing insights into their existing views of work and their preliminary 'intellectualized’ sense of how the new system would be used. The second round occurred shortly after the FPTs had begun using the systems, but before usage had become habituated. At this juncture, their sense of how the system would actually alter their work processes was becoming more concrete and perceptions of the discrepancies between 'old' and 'new' methods were likely to be most salient (Kim et al. 2005). A total of 46 RepGrids were completed, with most of the FPTs participating in two rounds of interviews. (Two participants were unavailable for the second round - one was on leave, the other resigned.) To ensure that our methods were consistently applied, one author conducted the interviews; the other participated only in the analysis and interpretation of results. Due to security concerns, tape recording was prohibited. Detailed notes were made instead, limiting the amount of narrative data that could be included in the presentation of our findings.

\section{RepGrid Interviews}

Traditional approaches to studying work design based on Job Characteristics Theory (JCT) begin with a limited number of analytical categories or dimensions, arguing that these dimensions are universally significant and have a predictable impact on job incumbents’ perceptions of work. These ‘top-down’ efforts seek to identify empirical regularities across organizations and jobs, ignoring job-specific differences and social influences (Ilgen and Hollenbeck 1991). In contrast, our investigation proceeded from the bottom up, insofar as we began with the particular - the participants’ personal construct systems - and moved toward the general in an effort to develop a richer, more finely-grained perspective on one particular type of work and the socio-cultural environment in which it is embedded.

Tapping into personal construct systems is challenging because people do not have direct access to the structure of their own cognitions (Walsh 1995) and generally know more than they 
Davis, Christopher J. and Hufnagel, Ellen M. MIS Quarterly 31 (2) June 2007, pp XX-XX

can easily verbalize (Hufnagel and Conca 1994). This is especially true of implicit knowledge that is embedded in routine work practices and everyday experience. Thus, understanding how people perceive the details of their work and the similarities and differences between and among them is key to understanding the connections they make in evaluating and responding to new stimuli (Polanyi 1966). RepGrid is well suited to this purpose because it was developed to access the similarities and differences individuals perceive in their interpersonal relationships during psychotherapy sessions (Kelly 1955/1963).

RepGrid is essentially a technique for conducting structured interviews. It differs from more traditional approaches in that most structured interviews begin with a fixed set of questions relating to the researcher's theoretical framework. Respondents are told what we want to know and, by exclusion, what we are not interested in knowing. Skilled interviewers then lead participants to elaborate on their initial answers, moving from the general question to more particular explanations. If our theory is correct and we have asked the right questions, we can draw meaningful conclusions from their answers, but only with respect to our original framework. In other words, we cannot know what we do not ask. If our objective is to explore how respondents view the world - the theories that guide their day-to-day decisions and actions - we have to approach things from a different angle and avoid imposing order on the domain prematurely. RepGrid does this by reversing the interview process, beginning with particular items of experience and moving toward more general explanations in an effort to tease out the logic by which the respondent integrates and differentiates these elements.

The RepGrid technique Kelly originally devised focused on the roles played by others within a participant's social network (the elements to be evaluated) and elicited the personal constructs that differentiate them. Using a dichotomous scoring system, the individual was then asked to indicate which construct label best described each element in turn. This approach was 
Davis, Christopher J. and Hufnagel, Ellen M. MIS Quarterly 31 (2) June 2007, pp XX-XX

easy to administer, and the results could be analyzed visually without disrupting the flow of the conversation. Over the years, however, the technique has been adapted for use in contexts other than individual psychotherapy sessions and statistical packages are now available to facilitate data analysis. These developments have led to some debate as to the most appropriate way to implement grid techniques.

All RepGrid approaches begin with the selection of a series of elements representing the phenomenon of interest. The elements are in effect the item stems the participant will evaluate and can be supplied by the researcher or elicited from the participants (Ryle 1975). The majority of studies in the psychology literature utilize individuals or roles as the elements to be evaluated (Neimeyer et al. 2002); however, business researchers have employed a wider range of elements, including work activities or tasks (Brook and Brook 1989; Smith 1980), methods of communication (Hutchison 1998), different types of information systems (Whyte and Bytheway 1996), and the activities that comprise the performance appraisal process (Wright and Lam 2002). Although some have indicated that the elements must be unique or non-overlapping (Hunter and Beck 2000), others have argued for less restrictive requirements (Neimeyer et al. 2002; Wright and Lam 2002), so long as the elements fall within the respondent's range of convenience ${ }^{2}$ (Fransella et al. 2004). For example, Neimeyer et al. (2002) advocate the use of heterogeneous elements to capture construct systems that are "representative, meaningful, and well differentiated” (p. 195). Given the dearth of published research on this aspect of element selection (Bell 2003), we opted to allow the respondents to identify their own elements - the tasks they viewed as integral to fingerprint work - and relied on a statistical package to cluster any similar or overlapping elements together in the analysis phase.

\footnotetext{
${ }^{2}$ Kelly's Range Corollary specifies that personal constructs are "convenient for the anticipation of a finite range of events only". Thus, range of convenience refers to the particular domain or perceptual field in which a specific personal construct has relevance from the participant’s perspective (Kelly 1955/1963: pp. 68-9).
} 
Once the pool of elements has been specified, the next step involves asking the participant to evaluate triads of elements, identifying perceived similarities and differences between and among them. Through this process, each participant develops a series of personallymeaningful scales that resemble a semantic differential scale (Osgood et al. 1957), but with one important difference. The bipolar constructs that anchor the endpoints are not nomological in nature; they are in fact highly personal, describing the dimensions that have meaning within the individual's own theoretical framework. After all possible combinations of elements have been assessed and the individual's personal constructs have been identified, respondents are asked to rate or rank each element using their own personal construct scales. These ratings can then be analyzed using standard statistical procedures to reveal the relationships between the elements and constructs, as perceived by the participant in the context of his/her own past experience (Fransella et al. 2004).

RepGrid researchers have investigated the relative merits of rating versus ranking as well as the length of the scales themselves, with some arguing for scale lengths that exceed the number of elements, to allow for maximum discrimination, and others for shorter 5- or 7-point scales, to facilitate grid administration (see Fransella et al. [2004] for a summary of research on these issues). Although longer scales provide participants with more freedom to discriminate, 5-point rating scales are easier to assess visually (Tan and Hunter 2002) and have demonstrated better retest reliability (Bell 1990). Because our approach involved having the participants examine and explain their own completed grids, we elected to use 5-point rating scales.

In our study, each round consisted of two interviews. At the outset of the initial interview, the participant was told that the research objective was to study the impact of NAFIS on the process and organization of fingerprint work. To create a list of tasks that make up an individual's experience of work, each respondent was asked: "What are the tasks that comprise fingerprint work?” By defining the universe of discourse in this way, the interviews focused on the same 
Davis, Christopher J. and Hufnagel, Ellen M. MIS Quarterly 31 (2) June 2007, pp XX-XX

class of experiences without controlling the discussion: participants were free to sequence, structure, and express their feelings and perceptions using their own language. As the participant responded, the interviewer recorded the words used to describe each task or element on an index card. Using the minimum context form described by Kelly (1955/1991), the individual tasks were then re-presented to the participant in successive triads; the participant was asked to consider each triad, identify the two tasks that were most similar, and explain how they were related to one another and different from the third task. These discriminations established the endpoints or poles of their personal construct scales.

As each interview proceeded, a technique called “laddering up” (Bannister and Mair 1968) was used to encourage elaboration of why specific differences were important. "Laddering down" was used when the personal construct identified by a participant was too general to fully explain the element triad under discussion (see Boland 2001; Reynolds and Gutman 1988; Tan and Hunter 2002 for further explanation of this technique.) This process generated a series of personal constructs that, in the eyes of the individual participant, differentiated the tasks involved in fingerprint work. An example illustrating the grid development process is provided in Figure 1.

Figure 1 about here

After the participant's ratings were recorded, completed grids were analyzed using RepGrid II (Shaw and Gaines 1990), a software package that uses two-dimensional cluster analysis to re-order the rows and columns, placing those with the most similar ratings together and calculating the city-block distance between similar constructs (Fransella et al. 2004). The output of this analysis is a re-ordered grid containing ratings of the original elements along each construct with dendograms (crow’s feet) illustrating the linkages or clustering of the constructs.

\section{Interpreting the Statistical Results}


Davis, Christopher J. and Hufnagel, Ellen M. MIS Quarterly 31 (2) June 2007, pp XX-XX

At this juncture, many researchers proceed to interpret the RepGrid output. In doing so, they risk prematurely introducing their own perceptions and biases into the process. To reduce the risk of bias, Thomas and Harri-Augstein (1985) introduced talkback to draw the participants back into their completed grids and enable them to interpret their own results. Talkback is an interview technique that encourages participants to examine their completed grids and systematically explore how the elements and personal constructs they supplied actually relate to one another. In the second round of interviews, talkback (and annotation of the printout) began with the clusters that were most closely aligned by the statistical analysis. It continued through a number of iterations with each participant, revealing the system of interrelated constructs representing the individual participant's view of the essential characteristics of fingerprint work. The results of this process are illustrated via the mini-grid shown in Figure 2, which represents a small piece of one FPT’s RepGrid, captured during the second round of interviews. (The tasks shown on the grid are described in more detail later in the paper.)

-- Figure 2 about here

\section{Drawing Inferences across Grids}

Grids produced during the first round of interviews provided a general understanding of the FPTs' daily work activities, the linkages between tasks, and their preliminary sense of how the new system would be used. Responses to the second round of interviews were more detailed, providing a richer perspective on the significance of their traditional work practices and their perceptions of the broader impacts of NAFIS. To aggregate the results of the RepGrid and talkback exercises and draw inferences as to the meaning the FPTs attached to their work, we partitioned the data into four categories based on expertise and experience. We then looked for similarities and differences in the clusters and explanations across annotated grids within each of the four groups: inexperienced novices, experienced novices, inexperienced experts, and 
experienced experts. This process resulted in the identification of nine themes, which relate to specific aspects of the FPTs work environment that would change in a significant way when the new system and accompanying procedural changes were fully implemented. Several of these themes were articulated in some way by all study participants regardless of prior experience or expertise. Others were more clearly associated with experience and/or expertise, reflecting the greater cognitive complexity and situated understanding that develops over time through experiential learning and exposure to a wide variety of work-related problems (Büssing and Herbig 2003).

Before presenting our findings, we briefly explain how fingerprint work was performed prior to the introduction of AFIS technologies. The overview is designed to introduce readers to this type of forensic work and explain the process model that guided the training of FPTs, providing the rationale for their work procedures. We then describe the major themes that emerged from our aggregate analysis and discuss the mitigating effects of expertise and experience.

\section{RESEARCH FINDINGS}

\section{Organization and Work Processes Pre-Automation}

Fingerprint work in the UK has traditionally been divided into two distinct work processes: verification of the identities of people arrested by police (ten-print verification) and identification of offenders responsible for a particular crime (scenes of crime mark processing). To provide an evidential basis for both processes, when an individual was charged with a crime, two sets of fingerprints were taken. One set was sent to Scotland Yard where it was added to the national fingerprint database and used to verify the person's identity. The second set was filed by the local fingerprint bureau for use in future criminal investigations. 
Davis, Christopher J. and Hufnagel, Ellen M.

MIS Quarterly 31 (2) June 2007, pp XX-XX

Ten-print identity verification and scenes of crime (SOC) work begin with a common artifact - the fingerprint - but they are quite different procedures. Identity verification involves comparing two sets of fingerprints taken under controlled conditions - the set taken at the time of arrest and those already on file as a result of previous arrests. All ten fingerprints are captured and the quality of the images is good. Print-to-print comparison is relatively simple requiring only confirmation that the prints captured by police and any prints already on file for that individual are identical.

SOC processing is a more challenging task, often shown in TV crime dramas. It involves identification of latent fingerprints or marks from materials found at a crime scene. Unlike the prints taken from individuals in police custody, these marks are often blurred, incomplete, and limited in number. A second difference is the absence of other identification data. In order to identify an offender, the latent mark was compared with the prints in the local ten-print collection. These searches required multiple, visual mark-to-print comparisons and were guided by protocols designed to ensure the integrity of the process and the credibility of any fingerprint evidence presented in court.

Over the years, techniques and tools such as classification and coding schemes, image comparators, and databases enabled the FPTs to adapt their work processes to increase the likelihood and speed of print identification, but the complexity of the fingerprint images made the process of searching for a match difficult and time-consuming. The ten-prints of candidate suspects retrieved from the files were compared individually with the latent print(s) via a painstaking process that required concentration and visual acuity. To minimize errors and optimize effectiveness, print comparison was preceded by a number of protocol-driven, preparatory activities. For example, the volume, completeness, and quality of the evidence were first assessed. If something crucial was missing, further processing would await its arrival. If the quality of the 
crime scene marks was too poor to meet the evidential threshold set by the courts, the job was recorded as insufficient and work stopped.

Once a case file was judged complete, the identification process began. If a list of suspects had been provided by police or the FPT knew of criminals in their area with a similar modus operandi, their ten-prints were retrieved and compared with the crime scene marks. This guided search process substantially reduced the time and effort required to examine large numbers of tenprints. Detailed comparison was undertaken using an image comparator to enlarge the print images two at a time. While viewing these magnified images, the FPT circled the unique features of each print, looking for multiple points of similarity. In some cases, further examination using a magnifying glass was required. If a consecutive sequence of matching points was found, the conclusion that the images were identical was recorded, the comparator screen was wiped clean, and the prints were passed to another expert for second checking. Checking is something of a misnomer because comparison was repeated from scratch. If the match was confirmed, a third recomparison was performed by another expert before the investigating officer was notified of the results.

Within a local bureau, FPTs were organized into relatively autonomous teams of five to eight members, each with its own expertise-based hierarchy. Each team was responsible for examining fingerprints from crime scenes in a specific geographic area. Team organization provided social cohesion both within the bureau and between the bureau and the investigators crime scene examiners, detectives, etc. Team members were typically aware of criminals operating in their assigned area and had established close working relationships with the investigators within that precinct. The team structure also provided considerable flexibility in terms of the way work was organized and assigned. 
At several sites, older fingerprint recognition technologies were already used to facilitate the identification process. These systems lacked the power and sophisticated search algorithms incorporated in NAFIS, providing limited support for specific tasks. For example, instead of using image comparators and magnifying glasses to examine prints, FPTs could display the images onscreen and adjust the magnification as necessary. Thus, these systems were direct substitutes for earlier devices and did not alter the underlying work processes or control logic. Furthermore, because these systems were not available in every bureau, the FPTs' occupationally-controlled credentialing process continued to require aspiring professionals to demonstrate mastery of manual fingerprint identification techniques and an understanding of the process logic that guided their use.

NAFIS was introduced to the fingerprint community as an innovation that would significantly increase the number of SOC identifications they could make, doing so in far less time than was previously possible. Although the NAFIS search and matching algorithms had already proven quite powerful in system testing, a number of critical issues surfaced during our interviews, including unanticipated reactions on the part of the FPTs whose work was radically altered by the new system.

\section{Perspectives on the Changing Nature of Fingerprint Work}

Table 2 presents the nine themes identified via comparison of clusters across respondent grids, describing how the FPTs expected NAFIS to affect their work practices when fully implemented and integrated into their daily routine. Some of these changes had already occurred during pilot testing; others were anticipated based on their early experiences with the system and understanding of the implementation goals. Although some of the labels we attach to these themes have obvious parallels with theoretical constructs found in the work design literature, the FPTs' explanations of their personal constructs go beyond the mere identification of task-related 
Davis, Christopher J. and Hufnagel, Ellen M. MIS Quarterly 31 (2) June 2007, pp XX-XX

changes, revealing the social relations and organizing logic that interconnects the tasks themselves and those who perform them. The narrative highlights the conflict produced by organizational attempts to redefine the FPTs' task environment without fully appreciating the professional values that guided actual practice. It also illustrates the fact that many of the job characteristics defined by existing theories tend to bring the objective and observable features of the task environment into high relief, while masking more important aspects of the social context that imbue certain tasks with meaning in the eyes of those who actually perform them.

Table 2 about here

Four broad categories are used to organize the exposition of themes, emphasizing their relevance to: the organization of the local bureaus, the task environment, the larger processes that frame the individual tasks, and the roles traditionally assigned to individual FPTs within their expertise-based hierarchies. Where relevant, the contrasting views of novice and expert FPTs are noted. Because the occupationally-defined control system that guided the FPTs' training and work practices on a national basis was designed to address the shortcomings associated with earlier manual operations, our initial presentation contrasts the manual approach and NAFISsupported work processes. Although less sophisticated automated systems were already in use at several of our study sites, no attempt had yet been made on a national basis to redesign the organizing logic or credentialing requirements around them. Thus, older technologies were largely used at the FPTs' discretion and did not significantly alter their perceptions of the process itself. Prior exposure to such systems did, however, affect some of the assumptions and concerns expressed by the more experienced FPTs. These differences are noted where relevant in the context of specific themes. Throughout the narrative, examples of the bi-polar personal constructs the FPTs used to discriminate between tasks are included in single quotes. Double quotes are used to bound specific explanations provided by the FPTs during talkback interviews. 


\section{Organizational Change}

The automation of work typically involves some restructuring of work assignments to accommodate or capitalize on software design (Sarter et al. 1997). Jobs can be more narrowly defined to increase specialization, enlarged to include a wider range of similar tasks, or enriched by increasing employee responsibilities and opportunities for advancement (Campion et al. 2005). The major organizational change that accompanied the introduction of NAFIS was a horizontal expansion of the FPTs' job scope to include more tasks without a concomitant increase in their planning and control responsibilities or the meaningfulness of their work.

Job Enlargement. The major organizational change occasioned by NAFIS was the devolution of responsibility for ten-print work from Scotland Yard to the local bureaus. Unlike earlier systems, NAFIS was designed to support both ten-print verification and SOC processing, eliminating the need for redundant databases and providing local access to the national fingerprint databases. As a result of this reassignment of duties, the FPTs expected to spend significantly more time simply verifying the identities of individuals in police custody - a task requiring quick turnaround to ensure that known criminals are not released prematurely. Furthermore, due to the rapid response requirement, all FPTs, regardless of rank or expertise, would share responsibility for this task.

Responses to this restructuring varied along the lines of expertise. Although the addition of ten-print verifications increased the already heavy 'clerical' workload of the novice FPTs, their concerns about this impending change were more than offset by the opportunity NAFIS provided for increased participation in 'real fingerprint work'. Where previously they had played a relatively minor part in the identification of criminals, novice FPTs would now be able to develop and utilize a wider variety of fingerprint skills. Working with fingerprints and participating in the 'discovery process' was quite different from the 'administrative' tasks typically assigned to them, offering them new challenges and a more visible and significant role in the identification of 
criminals. From the perspective of the expert FPTs, however, the addition of ten-print responsibilities increased the 'clerical' aspects of their jobs, adding more routine work to their assignments and distracting them from what they regarded as their most 'important' objective solving crimes.

\section{Task-level Changes}

Although the devolution of ten-print work to the local bureaus promised to significantly increase their workload, the FPTs also expected NAFIS to have a direct effect on SOC processing. Of particular concern was the system's impact on the variety of skills, abilities, and materials involved in the performance of fingerprint work. Previous discussions of variety as it relates to work have taken a broad view, differentiating between tasks based on characteristics such as their knowledge and skill requirements (Hackman and Oldham 1980), the physical and mental activities involved (McGrath 1984), and the extent to which tasks are well structured (Keen and ScottMorton 1978). Although our data yielded similar contrasts, closer examination of the FPTs personal constructs revealed finer-grained distinctions that have particular relevance in the context of technical work. To clarify these distinctions, we begin by looking at the most evident changes in the variety of tasks associated with SOC work. We then explore the significance of task intensity or focal length as it relates to the processing of fingerprints.

Task Variety. Prior to NAFIS, SOC identification encompassed a wide range of tasks involving the use of multiple information sources, different media and specialized equipment, and a combination of physical and cognitive skills. To identify the perpetrator of a crime, an FPT first inspected the case file, reviewing the evidence provided by police, making decisions as to its completeness, and assessing the quality of the crime scene marks provided. The marks themselves were inspected to determine which finger on which hand had produced them and to categorize them based on general physiological patterns (whorl, arch, or loop). With this information in 
hand, the FPT proceeded to search the available ten-prints for potential matches. The manual search process involved rapidly flicking through the cards, excluding those with different patterns from further consideration, and pulling those that resembled the crime scene mark(s) for closer inspection. Image comparators and magnifying glasses were used to compare each set of candidate ten-prints to the crime scene mark and identify finer-grained similarities and differences. If the local ten-print collection had been digitized, the preparatory tasks were the same but the search for candidate matches could be done by paging through on-screen print images instead of paper ten-print cards. Thus, the FPTs’ activities were quite varied, requiring physical movement, the use of specialized tools and techniques, and the ability to make rapid visual comparisons based on an understanding of the properties of human fingerprints.

With the introduction of NAFIS, many of the 'manual' tasks involved in SOC work were ‘automated' and some were eliminated. Much of what the FPTs regarded as 'preliminary work' work that utilized skills such as card flicking, digit determination, and pattern classification - was not required, and the specialized equipment that supported their 'decision making' was no longer needed. NAFIS databases could be easily searched to determine whether or not a suspect in police custody had a criminal history; marks found at a crime scene matched the ten-prints of a previous offender; or the ten-prints of a suspect matched the marks from an earlier crime scene. In fact, NAFIS was sufficiently powerful that even smudged or partial marks could often be identified.

The FPTs were impressed by the system's capabilities, but reactions to its effect on their task environment were mixed. Already accustomed to using computers for data entry, many novice FPTs, but especially those with relatively short job tenure, were excited by the prospect of working with NAFIS because it provided an opportunity to develop and utilize 'fingerprint' rather than 'clerical' skills. The skills they would need to be successful in their new assignments were, however, different from traditional fingerprint skills. Instead of mastering the intricacies of pattern 
identification and digit determination, or learning how to rapidly flick through ten-print cards 'manual' skills that took time and practice to develop - their new skill requirements were largely 'system-related' and involved learning how to effectively apply this powerful tool. The inexperienced experts were less enthusiastic in their response to NAFIS. Many associated 'clerical' and 'administrative' work with ‘computer' work, characterizing it as 'routine’ or 'requiring little or no judgment' and contrasting it with work that 'involves fingerprint expertise'. Regardless of experience levels, the expert FPTs were concerned that the system would now dictate how their work was done and that they would be "locked into using it" for most of the workday.

Task Intensity. Task variety is considered an important aspect of work because variety is believed to increase both the level of interest and developmental opportunities associated with a particular job and thus the job incumbent's experienced meaningfulness of work (Champoux 1991). The characterization of their work as more or less varied does not, however, shed light on the FPTs' most significant task-related concern. Every expert FPT as well as several novices who were nearing certification expressed the belief that NAFIS would increase the intensity or attentional demands of their work. Prior to NAFIS, work processes were deliberately designed to reduce the time spent viewing magnified print images, looking for minute differences between them. Studying and comparing two fingerprints require intense concentration and close attention to fine details. The rapid eye movement required to make these comparisons and the very short focal length made this work tedious and could produce severe headaches if done for long periods of time. Lapses in concentration could short-circuit the process, forcing the FPT to begin anew to ensure that significant features had not been overlooked.

NAFIS eliminated or automated many of the screening tasks that preceded manual and semi-automated searches. It also cast a wider net in searching for suspects, but it could not 
Davis, Christopher J. and Hufnagel, Ellen M.

MIS Quarterly 31 (2) June 2007, pp XX-XX

actually make an identification. Instead, it produced often lengthy lists of possible candidates which the FPTs were required to confirm or disconfirm via visual on-screen comparison. The FPTs' concerns about the increasing intensity of their work under NAFIS were revealed by the many contrasting terms they used to discriminate between tasks, including microscopic/ macroscopic, focus on fine detail/focus on whole print, broad search/one-to-one comparison, intensive/less intensive, superficial/in-depth, and involves patterns/involves characteristics. As the FPTs elaborated on these pairings, it became apparent that, due to the addition of ten-print work and the minute comparisons required for SOC identifications, they expected to spend considerably more time examining magnified print images at close range. Although of little import to the novices who had had limited involvement in the identification process, these newly-assigned duties were of great concern to the experts who feared that monotony and tedium would lead to an increase in error rates.

\section{Process-level Changes}

One reason JCT fails to provide a rich portrait of work in organizational settings is its focus on individuals’ perceptions of their own work to the exclusion of process-level issues and interdependencies (Campion et al. 2005). Work processes - the specific way in which tasks are ordered across time and place (Torraco 2005) - are typically more complex than simple job analysis implies because the actions of multiple actors can be combined in many different ways (Pentland 2003). Differentiating between task- and process-related issues can be difficult, however, because the two are often tightly linked in practice; task-level changes can beget process changes and process changes can alter both tasks and interdependencies (Crowston 1997). The process-related concerns discussed below can be distinguished from the task-related changes insofar as they relate to the strategy the experts employed to conserve scarce resources within their 
units while preserving the integrity of the identification process, as well as the reasoning that guided task assignments within workgroups.

Process Control. Two factors are key in understanding the rationale behind the FPTs' decision rules and the changes occasioned by NAFIS: the scarcity of expertise and the costs associated with errors. Because fingerprint expertise was developed via a lengthy apprenticeship requiring repeated practice, the FPTs considered expertise an especially scarce resource that had to be managed wisely and used to full advantage in the more crucial stages of the identification process to reduce the likelihood of errors. Possible errors included missed identifications, or failure to accurately identify a known criminal before further crimes are committed, and misidentifications, mistakenly declaring a match between two similar prints that actually belong to different individuals. Both types of errors can have a negative effect on the perceptions of police investigators and the general public; however, misidentifications are of particular concern because they not only undermine the credibility of the fingerprint profession, but can also lead to incarceration of an innocent person. Based on their training and experience, the FPTs believed that the major cause of misidentifications was inattention to detail, which was strongly associated in the experts' minds with the tedium involved in microscopic print examination.

To prevent misidentifications, the practices that had for decades guided SOC work were clearly hierarchical, specifying well-defined decision thresholds for determining whether or not to continue attempts to find a match at various stages of the process. The FPTs' goal was to rule out unlikely candidates as quickly as possible, thereby avoiding microscopic inspection if a match could be disconfirmed without it. Each mark was first compared to the elimination prints ${ }^{3}$ provided by people who had had incidental or routine contact with the crime scene. If the prints

\footnotetext{
${ }^{3}$ Elimination prints are taken from individuals who have had physical contact with a crime scene but are not suspects, e.g., family members, medical personnel, etc. They are used to determine which marks might have been left by the perpetrator(s).
} 
Davis, Christopher J. and Hufnagel, Ellen M. MIS Quarterly 31 (2) June 2007, pp XX-XX

matched, the FPT concluded that the mark had not been left by a perpetrator of the crime, discontinuing further work on that particular print. If the mark did not match any of the elimination prints, FPTs began the search for possible suspects by ruling out unlikely candidates using information provided by the investigators, their own knowledge of the local crime scene, and preparatory diagnostics such as pattern classification and macroscopic examination. Although missed identifications could and did occur as a result of these search-limiting activities, the FPTs work protocols were designed to balance quality assurance procedures, which ensured that their results could be used as evidence in court, against the need to make the best use of their time and expertise.

With the introduction of NAFIS, quality assurance procedures were altered in two ways. First, because NAFIS was designed to capture all actions relating to every crime scene mark, FPTs would now have to enter all elimination prints provided by police before launching a search, delete each of them when the search was finished, and formally certify that they had done so. ${ }^{4}$ Second, the bounded search techniques that limited actual print comparisons to only the most likely candidates gave way to a process called cold searching - searching the database with no preparatory screening work. Cold searching exploits NAFIS' ability to quickly compare a crime scene mark to the millions of prints on file and produce lists of possible matches, sequencing them from most to least likely based on a calculated similarity metric. As a result of its powerful search functions, NAFIS reduced the likelihood of missed identifications but could not prevent misidentifications. While it facilitated the ‘search’ for possible suspects, it could not actually make an 'identification'. The FPTs would have to visually compare the mark to each of the candidates in turn to determine whether or not a true match had been found. Whether successful

\footnotetext{
${ }^{4}$ The policy requiring deletion of elimination prints was meant to ensure that the prints of people who had never been arrested were not retained in the NAFIS database.
} 
or not, each comparison had to be logged so the entire process was well-documented. Thus, human verification continued to be an essential part of the process and the practice of discontinuing comparison at the earliest signs of a discrepancy was superseded by a rule that required continued microscopic comparison until all of the system's top-ranked matches had been disconfirmed or a match was identified.

Many expert FPTs regarded the new elimination procedures as needlessly complicated and time-consuming. As one seasoned veteran explained, adding elimination prints to the database only to have to remove them again "will take four to five times longer than the way we handle them today.” Another particularly frustrated FPT went so far as to characterize this new requirement as "stupidity gone mad." The contrasts made by others indicated the value they attached to their uniquely human skills and the shortcomings they associated with the system's matching algorithms. Although the system developers and police commissioners claimed that the system's impressive search speed obviated the need for manual searching, macroscopic print examination, and pattern classification to identify possible suspects, the expert FPTs argued that many system-generated candidates bore little resemblance to the crime marks they entered. As one explained, "Visual comparison copes with issues like skin elasticity that NAFIS can’t detect.” Another noted that, unlike NAFIS, qualified experts “don’t need a group of characteristics in close proximity to eliminate most suspects...” A third remarked that "because pattern is not a search criterion, NAFIS comes back with the most bizarre results, which we waste time documenting and eliminating.”

Procedural Justification. Prior to NAFIS, the protocols for SOC processing were designed to ensure that the logic by which identifications were made was consistently applied and the process could be clearly explained to non-technical jurors. Although contextual knowledge facilitated problem solving, increasing the salience of particular cues, the sequence of steps the FPTs 
performed to identify a mark had to be fully documented and justifiable. This important dimension of their work was highlighted by many of the expert FPTs who differentiated tasks based on whether they 'must be defensible' or 'require no defense' and whether tasks were 'protocol-driven' or could be done on a ‘discretionary’ basis.

Under NAFIS, many of the discrete steps outlined by existing protocols were merged, intertwined, and hidden from view by the system interface. Furthermore, because the system vendor considered the search and matching algorithms proprietary, training focused on teaching the FPTs how to use NAFIS without revealing how it actually worked. Concerned about their inability to describe the identification process in court, the expert FPTs struggled to understand the underlying logic, speculating about how the system produced candidate matches and tinkering with different features in an effort to test their theories and hypotheses. For the expert FPTs, trusting the system and accepting the candidate lists it produced ran counter to the rules of practice instilled in them by their occupational training, posing a threat to their credibility as expert witnesses in court. Anticipating the questions typically asked fingerprint experts, they needed to be able to explain how the suspect pools were identified and searched, and the process by which they arrived at their conclusions.

Task Interdependence. The unified workflow model that integrated the many functions of NAFIS was also a concern from the perspective of task assignments and resource utilization. Prior to NAFIS, SOC work was divided into a series of discrete steps that could be performed at different times by different individuals, depending on current workloads, staff and equipment availability, and expertise. This arrangement had two benefits. First, it enabled teams to optimize resource utilization by clearly delineating tasks that 'could be done by anyone' and tasks that 'required expert status'. When workloads were light, an expert FPT might handle a case from beginning to end, performing both 'clerical' or 'preparatory' tasks and more complex 'search and 
identification’ tasks. During busier times, however, tasks that required little supervision or technical expertise were assigned to apprentice FPTs. Second, once assignments had been made, each FPT had considerable autonomy and could elect to perform all tasks related to a case consecutively, or they could batch their work and perform the same task on multiple cases at a single sitting. Thus, most fingerprint tasks were relatively independent of one another and could be handled as 'sequential' activities or processed in 'parallel'.

Under NAFIS, tasks were merged into a single workflow that required each FPT to process a case from beginning to end before tackling the next job in the queue. ${ }^{5}$ Consequently, the task assignments of all FPTs would be essentially the same, regardless of their individual skills and expertise. From an individual perspective, the unified workflow model increased the interdependence of tasks as they related to a particular case, creating greater task identity but reducing individual autonomy in the bargain. Task identity increased because each FPT would now be responsible for completing a whole job rather than repeatedly performing one or more steps without ever achieving the final goal. At the same time, individual autonomy was reduced by the forced sequencing of tasks.

Not surprisingly, the novice and expert FPTs differed in their interpretations of this change. According to JCT, task identity provides individual workers with a sense of completion, increasing the experienced meaningfulness of work (Ilgen and Hollenbeck 1991). This was the case for the novice FPTs whose assignments had previously been limited to the 'preparatory' steps in the identification process, providing relatively little opportunity to carry a 'search' through to identification and thus solve an actual crime. From a group perspective, however, sequential variety - the ability to organize task assignments in different ways in response to specific

\footnotetext{
${ }^{5}$ Although the NAFIS workflow model could be tailored to fit existing local procedures, no incidents of such adaptation were seen during the course of this research.
} 
contextual cues or changing workloads (Pentland 2003) - was significantly reduced. This was of great concern to the experts because it diminished the autonomy of their workgroups, i.e., the flexibility teams had to cope with changing workloads and efficiently allocate scarce technical resources. Increased task interdependence also meant that existing approaches to the oversight and training of apprentices would have to be revised since specific tasks could no longer be individually assigned.

\section{Role-related Changes}

The organizational, task, and process-level changes highlighted above were helpful in understanding how the FPTs expected their work to change under NAFIS; however, the talkback interviews, where the FPTs discussed the significance of their personal constructs, painted a richer portrait of the role-changing aspects of the system and the subjective qualities of fingerprint work - its psychological meaning, motivational properties, and effects on the expectations and values of those who engage in it. Because roles are socially-defined by interactions between individuals within a particular work context (Katz and Kahn 1978), they are helpful in illuminating group dynamics and the continuously evolving social relationships that affect the way people experience and judge their work (Marchese 1998). These social dimensions are especially critical to understanding technical work that is organized along horizontal rather than vertical lines (Barley 1996).

Vertically-organized work in organizations rests on a managerial hierarchy that makes explicit the power and authority managers exercise over those who report to them. For example, managerial responsibilities typically include setting goals, establishing priorities, and allocating resources. In horizontally-organized work environments like the fingerprint bureaus, these processes tend to be controlled from within via an expertise-based hierarchy and collaboration among members of the community of practice (Hatchuel and Weill 1995; Whalley and Barley 
Davis, Christopher J. and Hufnagel, Ellen M. MIS Quarterly 31 (2) June 2007, pp XX-XX

1997). These arrangements are reinforced by the shared values that bind members of an occupational group to their work, and workers are often motivated by the implicit challenges involved in the work itself and the recognition they receive from other members of their collective (Zabusky and Barley 1996).

Several interwoven threads combine to form a tapestry that portrays the significance of social interactions within the fingerprint bureaus, the socially-constructed values that united the community of FPTs, and the changing relations between the FPTs, their managers, and other police units. Not surprisingly, the majority of comments regarding the role-changing effects of NAFIS emerged from the expert FPTs' explanations of how they expected the system to alter the science of fingerprint identification and the meaning and organization of their work.

Status and Expertise. The pre-NAFIS world of the FPTs was characterized by a clear demarcation of roles and responsibilities and expertise-based task assignment. For example, a large fingerprint unit would include several geographically-focused teams, each comprised of a mixture of novices and experts. The simplest work was typically assigned to the most junior members while the expert FPTs handled more complex cases as well as the second and third checking required to confirm identifications made by their peers. Thus, expertise and supervisory responsibility were tightly linked, creating an informal hierarchy within each team and a clear delineation between the tasks assigned to trainees versus those with greater expertise.

For the expert FPTs, one of the most unsettling aspects of NAFIS was the fact that the system did not reflect or support hierarchical task assignment, creating an opportunity for wholesale reform of existing fingerprint practices as well as discontinuation of the team structure and associated pay scales. Although no such changes had been announced or suggested, because the functionality of NAFIS was so comprehensive, the more senior FPTs feared that the contextual and semiotic knowledge that differentiated them from the apprentices would in time be devalued, 
leading to a flattening of their internal hierarchies, fewer opportunities for advancement, and a loss of status and prestige. Some felt that NAFIS masked the experiential basis of their work, allowing organizational norms to subsume the professional hierarchy that located them within their community of practice. For example, on the basis of pilot testing alone, one expert FPT concluded that "fingerprint skills that are essential in gathering prints at major crime scenes will be degraded over time due to the absence of experience with non-computer images and latent marks.”

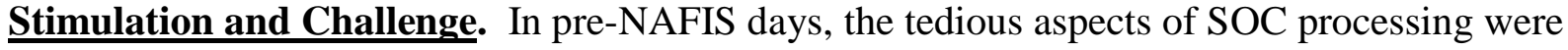
offset by the opportunities FPTs had for exploration and discovery, i.e., the chance to make an identification and help solve an important case. The more seasoned FPTs took pride in the intuitions that enabled them to zero in on possible suspects based on little more than police reports describing a crime and their knowledge of previous crimes committed within their precincts. Highly-motivated FPTs might take the initiative in an investigation, “ferreting out” additional information from the detectives, and using it to focus their searches. When an FPT was successful in making an identification, it was customary in many bureaus to ring a bell or award custody of a “cold search trophy" - a visible token that alerted the entire unit to the successful culmination of a job. Thus, creativity on the part of individual FPTs brought not only intrinsic rewards, but also recognition from their peers. The experts recognized that the system could produce significantly more identifications than their manual techniques; however, their early exposure to the system seemed to indicate that it would also eliminate many opportunities for creative discovery, reducing the sense of excitement and challenge that motivated them and made their jobs interesting.

Contribution to the Investigative Process. Fingerprint evidence is often key to the solution of criminal investigations; however, when cases are successfully concluded, the significance of the FPTs' contribution is frequently forgotten or downplayed by police investigators. The lack of appreciation for their efforts coupled with the separate locations in which the two groups work 
Davis, Christopher J. and Hufnagel, Ellen M.

MIS Quarterly 31 (2) June 2007, pp XX-XX

has, for many FPTs, created a sense of isolation from the rest of the police force. Unfortunately, the introduction of NAFIS did not improve the outlook for ongoing relations between these units. The system's search speed was impressive as was the volume of hits it produced, including some from 30-year-old cold cases. But, because the system effectively masked the FPTs' contribution, other members of the police force began to view the system as "a sort of identification machine" that required little more than a trained computer operator to successfully identify crime scene marks. To illustrate this perceptual shift, one FPT produced a widely circulated memo from management announcing the record number of "identifications made by NAFIS" during pilot testing - this memo made no mention of the efforts of its human operators. Not surprisingly, the FPTs felt that NAFIS would usurp what little recognition there was, leaving them more isolated and under-appreciated than ever.

\section{Expertise and Experience as Mitigating Factors}

Prior research on expert-novice differences (Glaser 1984; Lurigio and Carroll 1985) suggests that novices typically have less complex cognitive schemas than experts, organizing domain-specific knowledge around literal objects and surface features. Experts, on the other hand, have more detailed and meaningful cognitive schema, organizing their knowledge around principles that tend to subsume the literal objects. Our findings are consistent with these observations. As a group, the novice FPTs - particularly those in the early stages of their apprenticeships - identified fewer task elements, using broader, more objective personal constructs to compare and contrast them. For example, they were more likely to categorize individual task elements based on the nature of the task itself, who was qualified to perform it, and how the work was performed. In contrast, the expert FPTs decomposed their work into smaller task elements, making more finely-grained distinctions that helped clarify the process- and rolerelated effects of NAFIS. Their personal constructs spoke more directly to the way specific tasks 
fit within the overall decision making process, the particular expertise required to make certain judgments, and the role of the collective versus the individual in making them. Thus, their understanding was more closely tied to actual practice and the underlying logic of their historical work rules.

Although expert-novice differences were most evident in our initial analysis, prior experience with AFIS technologies also colored the FPTs’ perceptions of the system. Like Zuboff (1988), we found that more experienced users were better able to adjust their routines "to accommodate their understanding to the altered conditions of work,” demonstrating an increased “awareness of the continuities and discontinuities in the quality of their work experience” pre- and

post-NAFIS (pp. 13-14). While inexperienced FPTs were preoccupied with understanding how to use NAFIS and integrate it into their existing routines, experienced FPTs were more concerned about how NAFIS actually worked, i.e., how the algorithms produced the results, and whether or not the results could be relied upon. Conditioned by their exposure to less sophisticated fingerprint identification technologies - systems that could be used at their own discretion - they were especially concerned about the control NAFIS exerted over their work processes and their inability to decide if and when to use it.

\section{DISCUSSION}

The nine themes that emerged from our analysis illuminate the complex web of connections that comprised the FPTs' technology-in-use frames, guiding their interpretations of and responses to this change initiative. Prior research on technological frames points out the effect frame incongruence - differences in the assumptions and expectations of users, system designers, and managers - can have on implementation processes and outcomes (Orlikowski and Gash 1994). In contrast, our study focused exclusively on the technology-in-use frames of the intended users of NAFIS in an effort to understand how this particular occupational group responded to the 
Davis, Christopher J. and Hufnagel, Ellen M. MIS Quarterly 31 (2) June 2007, pp XX-XX

automation of their task environment. Our findings revealed a sort of internal frame incongruence - an inherent conflict between the cognitive frames that define the FPTs' occupational and organizational identities. The majority of our participants were fully qualified experts with relatively long job tenure. Thus, the frame incongruence that stood out most clearly in our analysis highlighted the cognitive dissonance they experienced as a result of perceived contradictions between the dictates of 'good practice', as defined by their credentialing organization, and the control logic embedded in NAFIS and endorsed by the vertical hierarchy through which they reported. This dissonance was a byproduct of their assumptions about the effect NAFIS would have on their production processes, the motivational aspects of their work, and status relations within their communities of practice.

\section{Transformation and Caretaking}

In discussing some of the anomalies associated with technical work in organizations, Whalley and Barley (1997) describe two key functions technicians perform in their work at the empirical interface: transformation and caretaking. The production aspects of technical work involve transforming material entities into symbolic representations, test results, and assessments that others who lack their specific knowledge and expertise rely on in the performance of their own work. Caretaking activities involve acting on the feedback technicians receive as to the effectiveness of these transformational activities and are designed to protect the integrity of the process itself - to ensure that both the material entities and their tools and techniques can be relied upon. The organizational and task-related themes noted previously relate most directly to the transformational aspects of fingerprint work. For example, within the fingerprint bureaus, transformational activities involved examining the evidence and crime scene marks, applying knowledge of local criminals and their "signatures" to sift through suspect pools, and utilizing scientific knowledge of the unique properties of fingerprints to arrive at a conclusion as to the 
identity of perpetrators. The process-related themes speak to the FPTs' caretaking responsibilities, describing how the organization of their work processes facilitated the allocation of scarce expertise and helped to ensure quality control objectives were met.

Although NAFIS effectively streamlined the FPTs' transformational process, eliminating many time-consuming preparatory tasks and reducing their dependence on skilled judgment to identify possible suspects, the addition of ten-print work and the unified NAFIS workflow model had a homogenizing effect on the FPTs' task environment. Together, these changes created the expectation that work assignments would be relatively undifferentiated in the future as traditional fingerprint expertise became less crucial and knowledge of the system became the new coin of the realm, eroding the foundation of their expertise-based hierarchy and occupational control system. The NAFIS workflow model was designed to integrate and facilitate what had been fairly cumbersome manual or semi-automated tasks. Unfortunately, it had further unintended consequences insofar as it fragmented the FPTs' inner visions of their work and the relational logic that guided it.

Perhaps most disturbing to the expert FPTs was the "ghost in the machine" - the search and matching algorithms that in effect mystified their production activities. Like the engineers in Pentland's (1995) study, the expert FPTs were often quite helpless to explain the system's output. Lacking an authoritative source to help them interpret the results, they could only speculate about how the software was designed and what they could do to influence its selections. They understood what NAFIS did for them in terms of the specific results it produced but, because the system’s algorithms were not explained or revealed through system use, they did not understand how or why it worked this way. For many, understanding the software became a different sort of challenge that required a new type of expertise - the ability to influence system outputs by outguessing the machine. 
By concealing the means of production - the algorithms themselves - NAFIS also increased the prominence and availability of the ends, creating the illusion that cases could be solved with the mere touch of a button and little or no understanding of the risks involved in such a seemingly simple approach to fingerprint identification. This illusion was highly motivating for the novice FPTs as it put them on a more equal footing with the experts; however, it obscured the intricacies involved in fingerprint identification behind a user-friendly interface and focused their attention on finding matches with minimal regard for the consequences that could ensue from even one misidentification. Based on their extensive training, the expert FPTs were conditioned to be skeptical of every match - to repeatedly check and recheck one another's results to be absolutely sure no mistakes had been made before reporting a successful identification. This preoccupation with quality control reflected their understanding of the inexactitudes of fingerprint science and their belief that misidentification represented a significant threat to the credibility of their profession. From their perspective, NAFIS was more than a simple substitute for their traditional tools - by increasing the attentional demands of their work (Martin and Wall 1989), it became a new source of (often uncontrollable) errors not covered by existing heuristics and practices. The process-related concerns they raised suggested that neither the risks associated with their work nor their caretaking role had been adequately considered by either the developers of NAFIS or the managers who redefined the control structure to accommodate it.

\section{Motivation of Technical Specialists}

Researchers who study the work of organizational professionals such as engineers and scientists have found that many who pursue technical callings are motivated by the challenge associated with the work itself rather than by formal reward systems or the promise of advancement up the organizational hierarchy (Zetka 2001; Farris and Cordero 2002). Ethnographic studies of technicians’ work reveal a similar orientation, pointing out that many 
technicians are motivated by love of the work they do, the challenges they face in solving new problems, and the centrality of the roles they play within their work communities (Zabusky and Barley 1996).

Although most of the experts felt their work was under-appreciated by others prior to NAFIS, they derived considerable satisfaction from the opportunities they had to demonstrate their expertise in solving especially difficult cases, and the recognition they received from their peers when they did so. But the thrill of the hunt that motivated them to go beyond their job description in hopes of solving important cases all but disappeared as the power of the system became evident during pilot testing. Some FPTs made a concerted effort to master the new system; however, when they were successful in making an identification, their results were ascribed to the system by those managing the project. As a result, the challenging aspects of fingerprint work and the sense of accomplishment the FPTs derived from it seemed destined to be usurped by the machine, further devaluing their individual contributions in the eyes of the larger organization.

Furthermore, as the importance of the team structure diminished, it seemed likely that the recognition they received from their peers might disappear as well.

\section{Occupational Identity within a Community of Practice}

Perceptions of similarities and differences provide insights into the psychological challenges individuals face as they construe changes in the world around them (Zuboff 1988), but they have important social implications as well, grounding the individual's sense of belonging to a larger community and providing a basis for the negotiation and exchange of meaning and values

(Kelly 1955/1991). Communities of practice are often cited as one of the hallmarks of knowledgebased work in organizations (DeSanctis and Poole 1994) and are also believed to be important in technical work settings where expertise is unevenly distributed and collective decision making is the norm (Cox 2005). This concept was originally articulated by Lave and Wenger (1991) to 
explain how apprenticeship programs facilitate the transfer of contextual knowledge and skills as newcomers to a discipline or field of work gradually become engaged in the socio-cultural practices of the larger community, constructing new identities that reflect their growing competence, and gaining the trust of those at the core of an established professional community. Thus, it has particular relevance in this case. ${ }^{6}$ "Communities of practice create value by connecting the personal development and professional identities of practitioners to the strategy of the organization” (Wenger et al. 2002: 17). Key to the successful formation and ongoing maintenance of such communities is recognition by management of the value-adding properties of horizontally-distributed knowledge and appreciation of the fact that expertise found at lower levels of the hierarchy develops through social interaction, ongoing dialog, and mutual engagement in problem-solving activities.

From a communities of practice perspective, the NAFIS implementation could be viewed as a step back in time because managers who oversaw the project focused exclusively on automating the visible, transformational tasks associated with fingerprint identification, ignoring the web of knowledge that connected the FPTs to their work and the importance of their expertisebased hierarchies in coordinating workflows, defining status and authority relations, and guiding the training and socialization of new entrants to their profession. "The shared understandings generated through intensive occupational socialization are typically enough to generate the commitment and solidarity required for making this type of hierarchical coordination system work effectively"; however, administratively-imposed technical innovations can threaten an occupational group’s sense of control, producing ‘tenacious resistance’ (Zetka 2001: p. 1511). Furthermore, radically changing social relations though automation can fundamentally alter the

\footnotetext{
${ }^{6}$ A similar notion underlies Zuboff's (1988) characterization of "informated” organizing strategies, which are designed to foster active engagement in increasingly automated work environments.
} 
professional identities of occupational communities, leading to role uncertainty and a reduction in their commitment to the work they do (Barrett and Walsham 1999). In the case of the FPTs, management's failure to adequately understand and appreciate their organizing logic and the role relationships defined by it created a sort of occupational identity crisis. Instead of embracing NAFIS as a time and labor-saving innovation, as management anticipated, the expert FPTs were more attuned to the effects it would have on their work as their occupational control system was dismantled and replaced by vertically-imposed rules and procedures that belied the complexity of their craft and the value of their situated knowledge and expertise.

\section{IMPLICATIONS FOR PRACTICE}

Orlikowski and Gash (1994) proposed the concept of technological frames as a vehicle for understanding how organizational stakeholders evaluate and experience technological change, providing insights into the nature and institutional influence of social cognitions. Our study extends prior research on technological frames by applying this lens to the world of professionalized technical work, where expertise and practice are tightly intertwined and occupational norms of practice provide the guiding logic and controls necessary to ensure knowledgeable performance. Our findings suggest that professional hierarchies embedded in traditional organizational structures pose unique challenges for vertically-managed change initiatives. Because their value systems are forged outside the boundaries of the organizations in which they operate, efforts to reform and restructure their work can run counter to their training and formally-certified expertise, producing cognitive dissonance and tensions that are not easily resolved in the local context in which that expertise is applied.

Of course, not all technical work in organizations is governed by formal professional norms and values, but externally-awarded certifications are common in many technically-oriented disciplines, including financial management, insurance and real estate, systems support, project 
management, and various medical support specialties. To the extent that organizations signal the value of these certifications by reimbursing employees for the costs of acquiring and maintaining them, they legitimize the role of these occupational groups and reinforce the importance of the knowledge and values circumscribed by them. Thus, it is not surprising to find that many technicians relate more strongly to their occupational groups than they do to the organizations that employ them (Barley and Kunda 2004). When this is the case, however, particular care must be taken to ensure that the professional value systems fostered by these occupational groups are considered prior to the design and implementation of systems that impinge upon them.

Although our findings relate most directly to projects that automate the work of corporate technicians with strong occupational ties, they also have implications for more broadly focused knowledge work systems. For example, they point out that the knowledge and expertise organizations value and seek to capitalize on may be neither clearly visible nor well-explained by mere observation of workflows and task assignments. Thus, traditional analysis techniques for mapping tasks and processes may miss or misrepresent the knowledge and understanding that resides in the connections between individuals, roles, and workplace artifacts. Furthermore, when design efforts focus solely on the observable, ignoring the socially-constructed aspects of work, the resulting systems may replicate and even improve measurable, organizationally-defined performance outcomes, while obscuring important aspects of the transformation process and making it difficult for users to understand and explain how the results are produced. By concealing process-related knowledge and understanding behind a seemingly user-friendly interface, such design approaches effectively widen the gap "between the function accessible to everyone and the machinery known by nearly no one” (Borgmann 1984: 47), leaving intended users feeling more distanced from the work itself. Our findings also reinforce the assertion that, when horizontally-distributed knowledge is nested in a vertically-organized management structure, 
those in traditional positions of authority "risk making decisions based on incomplete information, faulty understandings, and criteria that sacrifice long-run effectiveness” (Barley 1996: 437).

\section{IMPLICATIONS FOR RESEARCH ON SOCIAL COGNITIONS}

Studying social cognitions in organizational settings is inherently difficult because the phenomenon of interest is neither directly observable nor easily elicited from the minds of individuals (Walsh 1995). Thus, the best we can hope for in a study such as this one is a “privileged misty view of the world” of these technicians (Fransella et al. 2004) and their technology-in-use frames. The methods used in this study were specifically chosen to allow the FPTs to identify and evaluate the dimensions of their work that mattered most from their perspective and to engage them in the interpretation of the statistical results. However, the aggregation of results across respondents was ultimately performed by the researchers and thus represents our understanding of their personal construct systems.

On the one hand, the combination of quantitative and qualitative techniques - Repertory Grid plus talkback - yielded insights into the meaning of fingerprint work that might not have been revealed by more traditional structured interview techniques. On the other hand, the focal issues that did emerge were likely those most salient to the respondents at the time of each interview (Hufnagel and Conca 1994). Other equally important concerns might have been brought to the fore by different elicitation procedures or a different cognitive mapping technique. Until more is known about how the structure and content of cognitive frames can best be revealed, research on technological frames can benefit from methodological diversity and an openness to techniques that give study participants greater control over the assessment process to ensure that 
the knowledge and belief structures measured are those of the participants rather than the researcher (Walsh 1995).

Given the highly specialized nature of fingerprint work and the context in which it is performed, the question of generalizability cannot be ignored. We believe the insights obtained regarding the relationship between the FPTs’ occupational control structure and the organizational demands associated with NAFIS may shed light on other efforts to automate technical work, particularly where that work provides practitioners with a strong sense of occupational identity. Effecting change in such environments requires a deep appreciation for the nuances of the work itself, a situated understanding of the underlying principles that guide day-to-day practice, and recognition of the cognitive dissonance that can occur when the social identities of a community of practice conflict with or become fragmented by such automation efforts.

Although the participants represented a cross-section of the general population of FPTs, the views that dominated our analysis were those of the experts who are likely to be most resistant to change. Additionally, because the automated systems that preceded NAFIS varied from site to site, we may have overlooked or minimized important differences between them. There are many different views on how RepGrid should be applied, including how elements should be selected, whether rating or ranking is more appropriate, and the appropriate length of the rating scales. Although the choices we made can be justified based on previous adaptations of this technique, it is possible that our design choices and approach to aggregating the results may have introduced some bias. Hopefully, our explanations of these procedures will alert others to potential shortcomings in the techniques themselves or our application of them. While very labor-intensive relative to other data collection techniques, we believe the combination of qualitative and quantitative methods is a strength of this research and offers great promise for those who embrace 
Davis, Christopher J. and Hufnagel, Ellen M. MIS Quarterly 31 (2) June 2007, pp XX-XX the socio-cognitive perspective and seek to understand the multiple frames of meaning that affect users’ assumptions, expectations, and experience of technological change.

Finally, this study focused specifically on the period of early system use in an effort to tap into users' perceptions before usage had become habituated. Data collected at later points in this multi-year implementation may help shed light on how the technology was ultimately assimilated into the FPTs' work lives over time. 


\section{References}

Abbott, A. The System of Professions, University of Chicago Press, Chicago, IL, 1988.

Armstrong, T. and Eden, C. "An Exploration of Occupational Role: An Exercise in Team Development," Personnel Review (8:1), 1979, pp. 20-21.

Bannister, D. and Mair, J.M.M. The Evaluation of Personal Constructs, Academic Press, London, 1968.

Barley, S.R. "Technology as an Occasion for Structuring: Evidence from Observations of CT Scanners and the Social Order of Radiology Departments,” Administrative Science Quarterly (31:1), 1986, pp. 78-108.

Barley, S.R. "Technicians in the Workplace: Ethnographic Evidence for Bringing Work into Organization Studies," Administrative Science Quarterly (41), 1996, pp. 404-441.

Barley, S.R. and Bechky, B. "In the Backrooms of Science: The Work of Technicians in Science Labs," Work and Occupations (21), 1994, pp. 85-126.

Barley, S.R. and Kunda, G. Gurus, Hired Guns, and Warm Bodies: Itinerant Experts in a Knowledge Economy, Princeton University Press, 2004.

Barley, S.R. and Orr, J.E., "Introduction: The Neglected Workforce," in Between Craft and Science: Technical Work in U.S. Settings, S. R. Barley and J.E. Orr (eds.), Cornell University Press, Ithaca, NY, 1997, pp. 1-19.

Barrett, M. and Walsham, G. "Electronic Trading and Work Transformation in the London Insurance Market,” Information Systems Research (10:1), 1999, pp. 1-22.

Bechky, B. “Object Lessons: Workplace Artifacts as Representations of Occupational Jurisdiction,” American Journal of Sociology (109:3), 2003, pp. 720-752.

Bell, R. C. "Analytic Issues in the Use of Repertory Grid Technique," in Advances in Personal Construct Psychology, Vol. 1, G. J. Neimeyer \& R. A. Neimeyer (eds.), JAI, Greenwich, CT, 1990, pp. 25-48.

Bell, R.C. “The Repertory Grid Technique,” in International Handbook of Personal Construct Psychology, F. Fransella (ed.), John Wiley \& Sons, Ltd., Chichester, West Sussex, 2003, pp. 95-103.

Berger, P. and Luckmann, T. The Social Construction of Reality: A Treatise in the Sociology of Knowledge. Doubleday (Anchor Books), Garden City, NY, 1967.

Boland, R. “The Tyranny of Space in Organizational Analysis,” Information and Organization (11), 2001, pp. 3-23.

Borgmann, A. Technology and the Character of Contemporary Life, University of Chicago Press, Chicago, IL, 1984.

Brook, J. and Brook, R. "Exploring the Meaning of Work and Non-work,” Journal of Organizational Behavior (10:2), 1989, pp. 169-178.

Büssing, A. and Herbig, B. “Implicit Knowledge and Experience in Work and Organizations,” in C.L. Cooper and I.T. Robertson (eds.), International Review of Industrial and Organizational Psychology (18), 2003, pp. 239-280.

Campion, M., Mumford, T., Morgeson, F., and Nahrgang, J. “Work Redesign: Eight Obstacles and Opportunities,” Human Resource Management (44:4), 2005, pp. 367-390.

Champoux, J.E. “A Multivariate Test of the Job Characteristics Theory of Motivation,” Journal of Organizational Behavior (12:5), 1991, pp. 431-447.

Cox, A. "What Are Communities of Practice? A Comparative Review of Four Seminal Works," Journal of Information Science (31:6), 2005, pp. 527-540.

Crowston, K. “A Coordination Theory Approach to Organizational Process Design,” Organization Science (8:2), 1997, pp. 157-175. 
Darr, A. and Scarselletta, M. “Technicians, Clients, and Professional Authority: Structured Interaction and Identity Formation in Technical Work,” New Technology, Work and Employment (17:1), 2002, pp. 61-73.

Davidson, E. “Technology Frames and Framing: A Socio-Cognitive Investigation of Requirements Determination,” MIS Quarterly, (26:4), 2002, pp. 329-358.

Davidson, E. “A Technological Frames Perspective on Information Technology and Organizational Change,” Journal of Applied Behavioral Science (42:1), 2006, pp. 23-39.

DeSanctis, G. and Poole, M "Capturing the Complexity in Advanced Technology Use: Adaptive Structuration Theory,” Organization Science ( 5:2), 1994, pp. 121-147.

Farris, G.F. and Cordero, R. “Leading Your Scientists and Engineers,” Research-Technology Management (45:6), 2002, pp. 13-25.

Fiske, S., and Taylor, S. Social Cognition. Addison-Wesley, Reading, MA, 1984.

Fransella, F., Bell, R. and Bannister, D. A Manual for Repertory Grid Technique, John Wiley \& Sons, Ltd., Chichester, West Sussex, 2004.

Gallivan, M.J. "Managing to Change: How Diverse Stakeholders Interpret Organizational Communication about Change Initiatives,” IEEE Transactions on Professional Communication (44:4), 2001, pp. 243-266.

Gibson, C. "From Knowledge Accumulation to Accommodation: Cycles of Collective Cognition in Workgroups,” Journal of Organizational Behavior (22:2), 2001, pp. 121-134.

Glaser, R. “Education and Thinking,” American Psychologist (39), 1984: pp. 93-104.

Hackman, J. R., and Oldham, G. R. Work Redesign. Addison-Wesley, Reading, MA, 1980.

Hatchuel, A., and Weil, B. Experts in Organizations: A Knowledge Based Perspective on Organizational change (L. Libbrecht, Trans.), Walter de Gruyter, Berlin, 1995

Hodgkinson, G.P. “Cognitive Inertia in a Turbulent Market: The Case of UK Residential Estate Agents,” Journal of Management Studies (34), 1997, pp. 921-945.

Hufnagel, E.M. and Conca, C. "User Response Data: The Potential for Errors and Biases," Information Systems Research (5:1), 1994, pp. 48-73.

Hunter, M.G. and Beck, J.E. “Using Repertory Grids to Conduct Cross-Cultural Information Systems Research,” Information Systems Research (11:1), 2000, pp. 93-101.

Hutchison, J.R., "Using the Role Repertory Grid Technique for Item Generation in a Survey of Knowledge Use,” Journal of Constructivist Psychology (11), 1998, pp. 149-162.

Ilgen, D.R. and Hollenbeck, J.R. “The Structure of Work: Job Design and Roles,” in M.D. Dunnette and L.M. Hough (eds.), Handbook of Industrial and Organizational Psychology, $2^{\text {nd }}$ ed., Vol. 2, Consulting Psychologists Press, Palo Alto, CA, 1991, pp. 165-207.

Katz, D. and Kahn, R.L. The Social Psychology of Organizations, $2^{\text {nd }}$ ed., Wiley, New York, 1978.

Keen, P.G.W. and Scott-Morton, M. Decision Support Systems: An Organizational Perspective. Addison-Wesley, Reading, MA, 1978.

Kelly, G. A Theory of Personality: The Psychology of Personal Constructs, Norton, New York, 1955/1963.

Kelly, G. The Psychology of Personal Constructs, Norton, New York (reprinted by Routledge, London), 1955/1991.

Kim, S.S., Malhotra, N.K., and Narasimhan, S. “Two Competing Perspectives on Automatic Use: A Theoretical and Empirical Comparison,” Information Systems Research (16:4), 2005, pp. 418-432, 
Lave, J., and Wenger, E. Situated Learning: Legitimate Peripheral Participation. Cambridge University Press, Cambridge, 1991.

Lurigio, A. and Carroll, J. "Probation Officers' Schemata of Offenders: Content, Development, and Impact on Treatment Decisions," Journal of Personality and Social Psychology (48:5), 1985, pp. 1112-1126.

Marchese, M.C. "Some Factors Affecting the Relationship Between Job Characteristics and Job Worth: A Job-Role Interpretation,” International Journal of Organizational Analysis, October 1998, pp. 355-369.

Marsden, D. and Littler, D. "Exploring Consumer Product Construct Systems with the Repertory Grid Technique," Qualitative Market Research (3:3), 2000, pp. 127-144.

Martin, R. and Wall, T.D. “Attentional Demand and Cost Responsibility as Stressors in Shopfloor Jobs,” Academy of Management Journal (32:1), 1989, pp. 69-86.

McGrath, J.E. Groups: Interaction and Performance, Prentice Hall, Englewood Cliffs, New Jersey, 1984.

Neimeyer, G.J. and Neimeyer, R.A. "Relational Trajectories: A Personal Construct Contribution,” Journal of Social and Personal Relationships (2), 1985, pp. 325-349.

Neimeyer, G., Neimeyer, R., Hagans, C. and Van Brunt, D. "Is There Madness in Our Method? The Effects of Repertory Grid Variations on Measures of Construct System Structure,” in Advances in Personal Construct Psychology: New Directions and Perspectives, R.A. Neimeyer and G. J. Neimeyer (eds), Praeger, Westport, CT, 2002, pp.161-200.

Nelson, B.J. “Work as a Moral Act: How Emergency Medical Technicians Understand Their Work,” in Between Craft and Science: Technical Work in U.S. Settings, S. R. Barley and J.E. Orr (eds.), Cornell University Press, Ithaca, NY, 1997, pp. 154-185.

Orlikowski, W. "CASE Tools as Organizational Change: Investigating Incremental and Radical Changes in Systems Development,” MIS Quarterly (17:3), 1993, pp. 309-340.

Orlikowski, W., and Gash, D. “Technological Frames: Making Sense of Information Technology in Organizations,” ACM Transactions on Information Systems (12:2), 1994, pp. 174-196.

Orr, J.E. Talking About Machines: An Ethnography of a Modern Job. ILR Press, Ithaca, NY, 1996.

Osgood, C.E, Suci, G. and Tannenbaum, P.H. The Measurement of Meaning, University of Illinois Press, Urbana, Ill., 1957, pp. 155-159.

Pentland, B. T. “Organizing Moves in Software Support Hot Lines,” Administrative Science Quarterly (37:4), 1992, pp. 527-548.

Pentland, B. "Information Systems and Organizational Learning: The Social Epistemology of Organizational Knowledge Systems,” Accounting, Management \& Information Technology (5:1), 1995, pp. 1-21.

Pentland, B.T. “Sequential Variety in Work Processes,” Organization Science (14:4), 2003, pp. 528-540.

Polanyi, M. The Tacit Dimension. Peter Smith, Gloucester, MA, 1966.

Porac, J., Thomas, H., and Baden-Fuller, C. "Competitive Groups as Cognitive Communities: The Case of the Scottish Knitwear Manufacturers” The Journal of Management Studies (26:4), 1989, pp. 397-416.

Reynolds, T., and Gutman, J. “Laddering Theory: Method, Analysis and Interpretation,” Journal of Advertising Research (28:1), 1988, pp. 11-31.

Ryle, A. Frames and Cages: The Repertory Grid Approach to Human Understanding. Sussex University Press, Brighton, UK, 1975.

Sahay, S., and Robey, D. "Organizational Context, Social Interpretation and the Implementation and Consequences of Geographic Information Systems,” Accounting, Management \& Information Technology (6:4), 1996, pp. 255-282. 
Sarter, N., Woods, D. and Billings, C., “Automation Surprises” in G. Salvendy (ed.), Handbook of Human Factors \& Ergonomics, $2^{\text {nd }}$ ed., Wiley-Interscience, New York, 1997, pp. 1295-1327.

Shaw, M., and Gaines, B. RepGrid II Manual. Centre for Person-Computer Studies, Calgary, 1990.

Smith, M. “An Analysis of Three Managerial Jobs Using Repertory Grids,” Journal of Management Studies (17:2), 1980, pp. 205-213.

Stewart, V. Business Applications of Repertory Grid, $2^{\text {nd }}$ ed., Enquire Within, New Zealand, 1997.

Tan, F.B. "Exploring Business-IT Alignment Using the Repertory Grid," Proceedings of the 10th Australasian Conference on Information Systems, Wellington, NZ, 1999, pp. 931-942.

Tan, F.B. and Hunter, M.G. "The Repertory Grid Technique: A Method for the Study of Cognition in Information Systems,” MIS Quarterly (26:1), 2002, pp. 39-57.

Thomas, L., and Harri-Augstein, E. S. Self-Organised Learning: Foundations of a Conversational Science of Psychology, Routledge Kegan \& Paul, London, 1985.

Torraco, R.J. “Work Design Theory: A Review and Critique with Implications for Human Resource Development,” Human Resource Development Quarterly (16:1), 2005: pp. 85-109.

Van de Ven, A.H. “The Context-Specific Nature of Competence and Corporate Development,” Asia Pacific Journal of Management (21), 2004, pp. 123-147.

Walsh, J. P. "Managerial and Organizational Cognition: Notes from a Trip Down Memory Lane,” Organization Science (6:3), 1995, pp. 280-321.

Wenger, E., McDermott, R., and Snyder, W.M. Cultivating Communities of Practice. Harvard Business School Press, Boston, MA, 2002.

Whalley, P. and Barley, S.E., “Technical Work in the Division of Labor: Stalking the Wily Anomaly,” in Between Craft and Science: Technical Work in U.S. Settings, S. R. Barley and J.E. Orr (eds.), Cornell University Press, Ithaca, NY, 1997: pp. 23-52.

Wilensky, H. “The Professionalization of Everyone?” The American Journal of Sociology (70:2), 1964, pp. 137-158.

Whyte, G. and Bytheway, A. “Factors Affecting Information System’s Success,” International Journal of Service Industry Management (7:1), 1996, pp. 74-93.

Wright, R. P. and Lam, S.S.K., “Comparing Apples with Apples: The Importance of Element Wording in Grid Applications,” Journal of Constructivist Psychology (15:2), 2002, pp. 109-119.

Zabusky, S.E. “Computers, Clients, and Expertise: Negotiating Technical Identities in a Non-Technical World,” in Between Craft and Science: Technical Work in U.S. Settings, S. R. Barley and J.E. Orr (eds.), Cornell University Press, Ithaca, NY, 1997: pp. 129-153.

Zabusky, S.E. and Barley, S.R. "Redefining Success: Ethnographic Observations on the Careers of Technicians," in Broken Ladders: Managerial Careers in the New Economy, P. Osterman, (ed.), Oxford University Press: New York, 1996, pp. 185-214.

Zetka, J.R. "Occupational Divisions of Labor and Their Technology Politics: The Case of Surgical Scopes and Gastrointestinal Medicine,” Social Forces (79:4), 2001, pp. 1495-1520.

Zuboff, S. In the Age of the Smart Machine, Basic Books, New York, 1988. 


\begin{tabular}{|c|c|c|c|}
\hline & \multicolumn{2}{|c|}{$\begin{array}{c}\text { Prior experience with AFIS } \\
\text { technologies }\end{array}$} & \multirow[b]{2}{*}{ Total } \\
\hline & Inexperienced & Experienced & \\
\hline Novice FPTs & 2 & 8 & 10 \\
\hline FP Experts & 7 & 7 & 14 \\
\hline Total & 9 & 15 & 24 \\
\hline
\end{tabular}

\begin{tabular}{|c|l|}
\hline Level of Analysis & \multicolumn{1}{|c|}{ Themes } \\
\hline Organization & Job Enlargement \\
\hline Task & $\begin{array}{l}\text { Task Variety } \\
\text { Task Intensity }\end{array}$ \\
\hline Process & $\begin{array}{l}\text { Process Control } \\
\text { Procedural Justification } \\
\text { Task Interdependence }\end{array}$ \\
\hline Role & $\begin{array}{l}\text { Status and Expertise } \\
\text { Stimulation and Challenge } \\
\text { Contribution to the Investigative Process }\end{array}$ \\
\hline \multicolumn{2}{|l}{ Table 2. Themes by Level of Analysis } \\
\hline
\end{tabular}




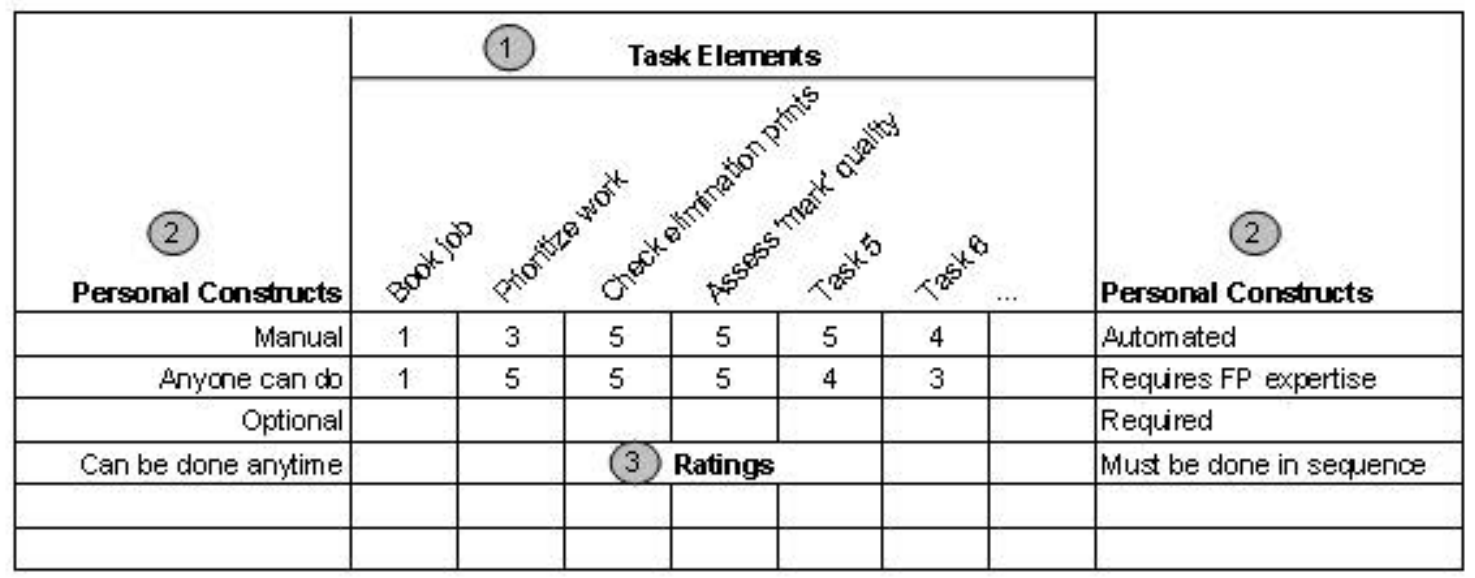

Step 1. Participart identifies tasks that com prise fingerprint work

Step 2. Participart assessestriads of task elements, identifying similarities and differences, yielding a series of personal construct scales (e.g., Manual/Automated, Anyone can doRequires fingerprint expertise, etc.)

Step 3. Participart evaluates each task elemert on a 5-pt. scale using own Personal Constructs (e.g., task element "Prioritize work" scored a 3 on the scale "Manual/Automated" and a 5 on the scale of tasks

"Anyone can do:Requires fingerprirt expertise"

\section{Figure 1. Grid Development Example}




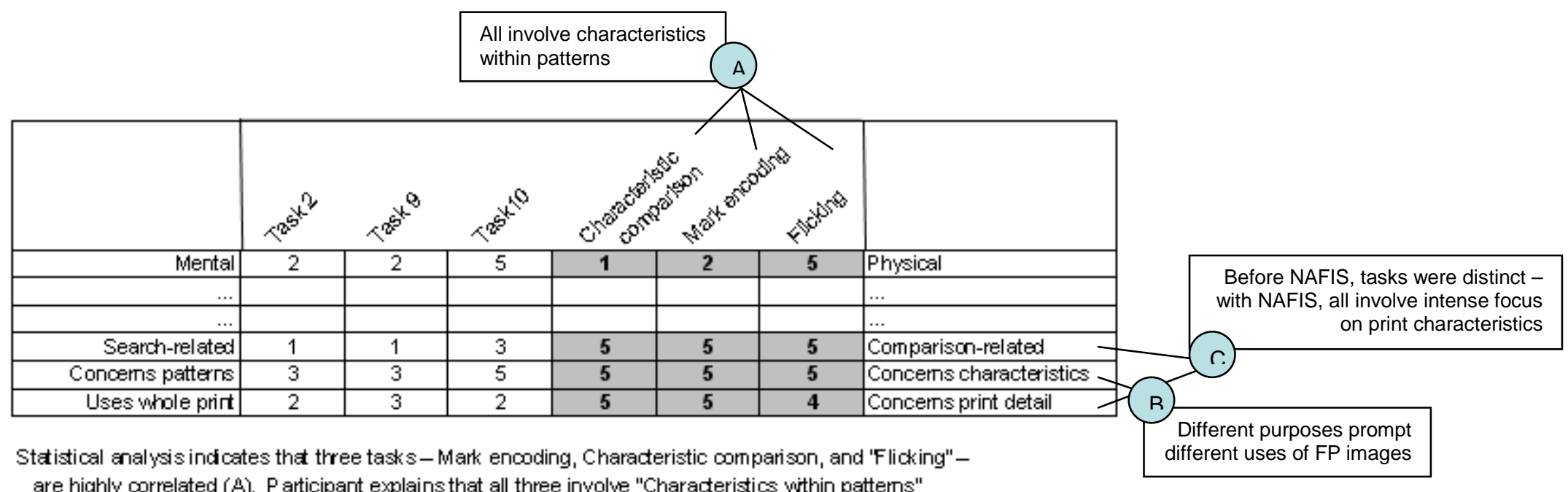
are highly correlated (A). P articipant explains that all three involve "Charaderistics within patterns"

Staistical analysisindicates that tree personal construd scales are related on two levels. The scales labeled

"Concerns paternsiConcerns charaderistics" and "Uses whole pritt/Concerns print detail" are most dosely aligned.

P oint of intersedion (B) is explained by the participant as indicating that "Different pumposes prompt dfferent uses of fingemrint images.

Second level relationship (C), conneds all three personal constructs and is explained by the observation that

"Before NAFIS, all tasks were distinct; with NAFIS, all involve intense focus on print charaderistics (details)".

Inspection of the mini-grid reveals a further difference -- both "Mark encoding" and "Characteristic com parison" fall at the "Mental" end of another scale, while 'Flicking" was considered a completely "Physical" activity by this FPT.

Observing similar discriminations and interpretations on the grids of multiple FP Ts led to the identification of "Task Intensity" important dimension for understanding how fingerprint work was altered by the introdudion of NAFIS.

\section{Figure 2. Interpretation of a Re-ordered Grid: Emergence of a Theme}

